\section{InDret}

2.2021

José Massaguer

Universidad de Murcia

\title{
Las creaciones publicitarias protegibles mediante derecho de autor: propuestas creativas, conceptos publicitarios, creatividades e ideas publicitarias
}

\begin{abstract}
Sumario
La doctrina de los autores se ha esforzado en negar que las ideas publicitarias puedan protegerse mediante derecho de autor, y muy poco en explicar qué son las creaciones publicitarias a las que el art. 21 I de la LGP reconoce la condición de categoría de creación intelectual protegible por medio de derecho de autor distinta de las obras literarias, artísticas o científicas del art. 10.1 de la LPI. En este trabajo me propongo demostrar que las genuinas creaciones publicitarias son lo que en el sector se conoce como "propuesta creativa", "concepto publicitario" y "creatividad", y la sustancia de todas ellas, a saber: las "ideas publicitarias" que componen el discurso publicitario que expresan y los recursos argumentales y de forma interna que lo articulan con el grado de individualidad suficiente para que se reconozcan en materiales publicitarios concretos cuya forma externa es diversa.
\end{abstract}

\begin{abstract}
Academic opinion has been intent on rejecting that advertising ideas can be protected under copyright laws, but not so on identifying which are the advertising works considered singular copyrightable intellectual creations under article 21 I of the General Advertising Law even though they are distinct from the literary, artistic or scientific works provided in article 10.1 of the Intellectual Property Law. This piece shows that genuine advertising works are what is known in the sector as "creative proposal", "advertising concept", "creativity", and their common essence, namely the "advertising ideas" that shape the advertising message and the thematic and formal resources used to express it with sufficient individuality to be recognized in concrete advertising materials having a different external form

Title: Legal protection of advertising works (creative proposal, advertising concept, creativities and advertising ideas) under copyright

Palabras clave: Publicidad; derecho de autor; obra protegible mediante derecho de autor; concepto publicitario, creatividad y propuesta creativa; protección de las ideas publicitarias
\end{abstract}

Keywords: Advertising; copyright; copyrightable works; advertising concept, creativity and creative proposal; protection of advertising ideas

DOI: $10.31009 /$ InDret.2021.i2.01 


\section{InDret}

2.2021

Recepción

11/01/2021

Aceptación

07/03/2021

Índice

\section{Introducción}

2. Consideraciones generales

3. Reconocimiento legal de la protección de las creaciones publicitarias por medio de derecho de autor

4. Creaciones publicitarias objeto de derecho de autor

4.1. Creación publicitaria, discurso publicitario y transversalidad de su expresión

4.2. Objeto de la creación publicitaria

a. Creación publicitaria y proceso publicitario

b. Creación publicitaria y objeto del contrato de creación publicitaria

c. Creación publicitaria, propuesta creativa, concepto publicitario, creatividad...

d. (sigue) ... y la sustancia de todo ello: las ideas publicitarias

4.3. Conformidad con la definición de obra según el Tribunal de Justicia de la Unión Europea

5. Alcance de la protección de la creación publicitaria mediante derecho de autor

6. Aplicación del régimen jurídico general sobre derecho de autor

6.1. Requisitos sustantivos para la efectiva protección de las creaciones publicitarias mediante derecho de autor

6.2. Atribución de la protección y presunción de cesión de derechos de explotación

7. Bibliografía

8. Tabla de sentencias citadas

Este trabajo se publica con una licencia Creative Commons Reconocimiento-No Comercial 4.0 Internacional @) 


\section{Introducción* **}

Este trabajo tiene por objeto revisar el estado de opinión dominante sobre la protección jurídica de las creaciones publicitarias por medio de derecho de autor y defender que esas creaciones, a pesar de no ser obras literarias, artísticas o científicas del art. 10.1 del Real Decreto Legislativo 1/1996, de 12 de abril, por el que se aprueba el texto refundido de la Ley de Propiedad Intelectual, regularizando, aclarando y armonizando las disposiciones legales vigentes sobre la materia (en adelante, LPI), constituyen una singular categoría de creación intelectual igualmente protegible mediante derecho de autor, como se sigue del art. 21 I de la Ley 34/1988, de 11 de noviembre, General de Publicidad (en adelante, LGP). En particular, las creaciones publicitarias que, como tales, pueden protegerse mediante esta modalidad de protección jurídica son, a la vista del llamado proceso publicitario y de la delimitación legal del objeto del contrato de creación publicitaria, lo que en el sector se conoce como "propuesta creativa", incluidas sus partes (el "concepto publicitario" y la "creatividad”) y su sustancia, esto es, las "ideas publicitarias” que componen el discurso publicitario (persuasivo o institucional) expresado en el material publicitario y los recursos argumentales (contenido) y de forma interna (presentación, estructuración, ordenación e interrelación) que lo articulan, siempre que posean el grado de individualidad necesario para que unos y otros se reconozcan en materiales publicitarios (distintos de los originales) cuya forma externa es diversa, con la consecuencia de que la tutela de las creaciones publicitarias alcanza a los materiales publicitarios que incorporan los elementos fundamentales y característicos del discurso y recursos publicitarios que expresan las ideas publicitarias en la propuesta creativa ${ }^{1}$.

El reconocimiento de la protegibilidad de las creaciones publicitarias mediante derecho de autor es una constante en nuestra legislación especial sobre publicidad (art. 21 I LGP y antes art. 70 de la Ley 61/1964, de 11 de junio, por la que se aprueba el Estatuto de la Publicidad), como también lo es su omisión en el catálogo de obras protegibles que recoge la legislación general de propiedad intelectual (art. 10.1 LPI). No puede negarse que aquel reconocimiento y sus desarrollos han merecido la atención de la doctrina de los autores, tanto bajo el Estatuto de la Publicidad y antes de la aprobación de la Ley de Propiedad Intelectual de $1987^{2}$, como bajo la LGP de 1988 y el Texto

\footnotetext{
* Este trabajo está dedicado, con gratitud y aprecio, al profesor Gerhard Schricker, mi maestro alemán, cuyo consejo y oientación fueron decisivos en la elección del tema de mi tesis doctoral y, con ello, en el nacimiento de mi interés por la protección jurídica de la propiedad industrial e intelectual y el Derecho de la competencia, que tan fundamentales han sido para mi carrera académica y profesional.

** Para la preparación de este trabajo me he beneficiado de las explicaciones y observaciones de José Agra y Guillermo Garattoni, creativos publicitarios de CPWORKS, que me han explicado el proceso de preparación de una campaña y un anuncio, desde el planteamiento de su encargo hasta la realización de la campaña y la producción del anuncio, con especial atención al iter y resultados de la etapa creativa y a la ideación de la campaña o anuncio. Naturalmente, los errores que al respecto se pudieran encontrar solo son responsabilidad mía. Asimismo, en las etapas iniciales de este trabajo conté con la valiosa ayuda de mis compañeras Ana Ortega Redondo e Irene Ortega Andrades para la localización, selección y revisión de los materiales manejados en su preparación.

${ }^{1}$ La protección jurídica de las creaciones publicitarias que aquí se denominan propuestas creativas, conceptos publicitarios e ideas publicitarias mediante derecho de autor fue planteada y defendida por el profesor Gerhard SCHRICKER (1996) y (2004).

${ }^{2}$ Carlos Fernández NovoA (1989).
} 
Refundido de la LPI de $1996^{3}$. Sin embargo, la posición mayoritaria sobre el particular no es a mi juicio convincente. Es cierto que no se ha cuestionado que las creaciones publicitarias puedan ser y de hecho sean objeto de derecho de autor, pero no lo es menos que no se han definido y caracterizado de forma acabada y útil como categoría de creación intelectual protegible, que se ha entendido o sobreentendido que la creación publicitaria es el material publicitario, esto es, el cartel, la cuña radiofónica, el spot televisivo, etc., y en fin que se ha negado, con meritorias excepciones ${ }^{4}$, que las ideas publicitarias expresadas en esos materiales puedan ser protegidas mediante derecho de autor con razonamientos que, a mi modo de ver, abundan en estereotipos y lugares comunes. Siempre desde mi punto de vista, ha faltado y falta en nuestra literatura jurídica un trabajo que, como requieren los términos en que se reconoce legalmente su protegibilidad mediante derecho de autor y la ubicación de la norma que así lo establece en una ley especial (extravagante a la LPI), asuma la especialidad que, entre las creaciones intelectuales, corresponde a la creación publicitaria y desentrañe su verdadera sustancia. En este sentido, a mi modo de ver sorprende la escasa atención que, para definir la creación publicitaria como objeto protegido por medio de derecho de autor, se ha prestado al proceso de elaboración de la publicidad, a pesar de ser necesario, a mi juicio, para comprender qué es una creación publicitaria y respecto de ella qué son las ideas publicitarias y cuál es su materia y cuál su forma y grado de expresión. Y sorprende especialmente que, sobre ello, no se haya reparado en que la prohibición de protección de las ideas mediante derecho de autor solo alcanza a las ideas "en sí" (art. 9 Acuerdo sobre los ADPIC y art. 2 del Tratado OMPI sobre Derecho de Autor), pero no per se, y que, igualmente, se hayan pasado por alto las implicaciones que se siguen de que la creación publicitaria (cuya protección mediante derecho de autor se reconoce) se haya configurado como resultado del contrato de creación publicitaria (art. 21 I LPI), de que la prestación comprometida por el creativo en virtud de este contrato se haya definido como "idear" (art. 20 LGP) y, por último, de que se atribuya una exclusiva sobre las ideas publicitarias (art. 14 LGP).

En pocas palabras: parecería que la doctrina dominante se ha esforzado en negar sin matices que las ideas publicitarias puedan ser protegidas mediante derecho de autor y en hacerlo en un marco teórico general, y muy poco en cambio en explicar qué las creaciones publicitarias son susceptibles de ser objeto de derecho de autor, a pesar de que así se proclama expresamente en el art. 21 I de la LGP. De ahí que, aunque no se hayan producido cambios en el tratamiento legal de esta materia, parezca oportuno enfrentarse nuevamente a la protegibilidad de las creaciones publicitarias por medio de derecho de autor. Y ello, no solo para la fijación más precisa y mejor comprensión de las creaciones intelectuales protegidas por derecho de autor en el ámbito de la actividad publicitaria sino sobre todo para reevaluar el alcance objetivo de esta protección y precisar el contenido de la cesión de derechos sobre las creaciones publicitarias, sea de la que se presume con carácter general, sea de la que se haya pactado. Antes de hacerlo, sin embargo, conviene dejar sentados los principios del derecho de autor que más característicamente configuran el escenario en el que se asienta el objeto de este estudio.

\section{Consideraciones generales}

\footnotetext{
${ }^{3}$ Concepción SAIZ (1998); Rafael SÁNChEZ ARISTi (2000); José M. ${ }^{a}$ DE LA CuESTA (2002); Rafael JimÉNEZ DE PARGA (2003); Emilio LÁZARo (2009); Anxo TATo (2017).

${ }^{4}$ Rafael SÁNCHEZ ARISTI (2000), págs. 30 a 35.
} 
Los sistemas de propiedad industrial e intelectual se estructuran en torno a cuatro capítulos, a saber: objeto, requisitos, efectos (que comprenden, entre otros extremos, alcance objetivo y contenido sustantivo) y terminación de la protección. Esto es evidente. Y, por lo que importa, también lo es que sistemáticamente son cosas distintas la creación que puede ser protegida, en este caso, por medio de derecho de autor (art. 1 LPI) y los requisitos materiales o positivos que esa creación debe poseer, no para ser una creación de las que pueden protegerse por medio de derecho de autor, que es un dato previo, sino para ser efectivamente protegida o, si se prefiere, para merecer la tutela que proporciona el derecho de autor (art. 10.1 inciso primero LPI). En efecto, una composición musical es una creación intelectual (por lo que, por su naturaleza, puede ser objeto de derecho de autor) aunque no sea original (por lo que sus características, que no su naturaleza, impiden que sea protegida en efecto). A pesar de ser obvio, es oportuno dejarlo dicho porque la doctrina de los autores parece haber pasado por alto que la determinación de que las creaciones publicitarias son una categoría de creación intelectual susceptible de ser tutelada por medio de derecho de autor no se encuentra en la legislación de propiedad intelectual, sino en la legislación sobre publicidad, y con ello también que las disposiciones de la LGP son la primera fuente de definición y caracterización de lo que sea una creación publicitaria, también como creación intelectual protegible por medio de derecho de autor.

En relación con lo anterior no estará de más advertir que, con arreglo a los arts. 1 y 10.1 de la LGP, solo las creaciones intelectuales que sean obras literarias, artísticas o científicas pueden ser protegidas mediante derecho de autor ${ }^{5}$ (si reúnen los requisitos materiales exigidos al efecto). Como se ha dicho entre nosotros, la indicación de que las creaciones intelectuales protegidas son obras literarias, artísticas o científicas no es solo una clasificación, sino ante todo una delimitación normativa del ámbito de aplicación de la LPI y así de las creaciones intelectuales protegibles mediante esta modalidad de propiedad intelectual ${ }^{6}$. Sin perjuicio de la interpretación amplia que en este contexto corresponde a las categorías de lo literario, artístico o científico, las obras de esta naturaleza no forman un catálogo excluyente de creaciones protegibles o, desde otro ángulo, la protección mediante derecho de autor puede extenderse legalmente a creaciones intelectuales de otra naturaleza, como evidencia el reconocimiento de que puedan protegerse por medio de derecho de autor las colecciones (art. 12 LPI) o, bien miradas las cosas, los programas de ordenador, que han necesitado de una asimilación positiva (formal) a las obras literarias para que su tutela quedara encuadrada en el derecho de autor (art. 10.1.i LPI) ${ }^{7}$. Y esto es justamente lo que sucede con las creaciones publicitarias (art. 21 I LGP) ${ }^{8}$.

Desde otra perspectiva, la creación intelectual susceptible de ser objeto de derecho de autor queda perfilada por dos condiciones negativas. Por un lado, la creación protegible es una expresión del genio o espíritu humano, y no las ideas, procedimientos, métodos de operación o conceptos matemáticos en sí (art. 9.2 del Acuerdo sobre los ADPIC y art. 2 del Tratado OMPI sobre Derecho de Autor). Este principio se encuentra incorporado al Derecho de la UE y, en particular, a la definición de obra o creación intelectual protegible mediante derecho de autor de

\footnotetext{
${ }^{5}$ Ulrich LOEWENHEIM (2020), § 1 UrhG, Rn. 2.

${ }^{6}$ Rodrigo BERCOVITZ (2017), pág. 160.

${ }^{7}$ Rodrigo Bercovitz (2017), pág. 160.

${ }^{8}$ Esta solución evita de raíz la necesidad de las construcciones creativas de lo que es literario, artístico o científico en este ámbito, como en cambio fue necesario hacer en la doctrina alemana para incluir las creaciones publicitarias entre las creaciones protegidas por derecho de autor: vid. Gerhard SCHRICKER (1996), págs. 816 y 817.
} 
la Directiva 2001/29/CE relativa a la armonización de determinados aspectos de los derechos de autor y derechos afines a los derechos de autor en la sociedad de la información (la "Directiva 2001/29/CE") ${ }^{9}$. De igual modo, su vigencia en nuestro ordenamiento jurídico interno está fuera de duda y, en particular, ha encontrado expresión en materia de protección de programas de ordenador (arts. 96.4 y 100.3 LPI), ha sido proclamada por los tribunales con carácter general ${ }^{10} \mathrm{y}$ es aceptada generalmente en la literatura jurídica ${ }^{11}$. Pero ello no debe impedir, ya que - como dije- se excluye su protección en sí, pero no per se, que la idea esté protegida mediante esta modalidad de protección jurídica en cuanto sea concepción de una obra que se incorpora a su concreta realización y se reconoce en ella por sus elementos y rasgos característicos ${ }^{12}$.

En fin, la utilidad práctica que pueda tener la creación intelectual no es circunstancia que la excluya de ser objeto de derecho de autor ${ }^{13} \mathrm{ni}$, desde otro ángulo, que exija un especial nivel de originalidad para reconocer su protección ${ }^{14}$. Ahora bien, es circunstancia que, por la naturaleza de las cosas, estrecha el margen de la originalidad, hasta incluso hacerlo desaparecer donde la idea se fusione con la expresión ${ }^{15}$, puesto que la protección jurídica mediante derecho de autor no alcanza a los elementos expresivos debidos a la función de la creación considerada ${ }^{16}$.

\section{Reconocimiento legal de la protección de las creaciones publicitarias por medio de derecho de autor}

Como objeto protegido por derecho de autor o, más precisamente, como bien susceptible de ser protegido por esta modalidad de propiedad intelectual, la obra es una creación intelectual (art. 1 LPI, arts. 2 a 4 de la Directiva 2001/29/CE ${ }^{17}$ y, como se ha visto, es en particular una creación del

\footnotetext{
${ }^{9}$ SSTJUE Gran Sala, 13.11.2018, asunto C-310/17, M. Vilaras (Ponente), "Levola Hengelo BV c. Smilde Foods BV" (ECLI: EU:C:2018:899), aptdo. (39); 3a ${ }^{\text {a }}$ 12.9.2019, asunto C-683/17, J. Malenovský (Ponente), "Cofemel - Sociedade de Vestuário, S.A. c. G-Star Raw CV" (ECLI: EU:C:2019:721), aptdo. (29); 5a, 11.8.2020, asunto C-833/18, E. Juhász (Ponente), “SI y Brompton Bicycle Ltd c. Chedech/Get2Get” (ECLI: EU:C:2020:461), aptdo. (27).

10 SSAP Madrid, Civil 28 a , 11.1.2007, Magistrado Ponente: Rafael Sarazá Jimena, “Comunicación persuasiva” (ECLI: ES:APM:2007:625), Civil 28ª , 11.10.2007, Magistrado Ponente: Enrique García García, “Lotería Elegida” (ECLI: ES:APM:2007:14578).

${ }^{11}$ Por todos, Rodrigo BercovitZ (2017), págs. 167-168, y Ulrich Loewenheim (2020), § 2 UrhG, Rn. 73.

${ }^{12}$ Rafael SÁNCHEZ ARISTI (2000), págs. 30 a 35, y nuevamente un apunte en Rafael SÁNCHEZ ARISTI (2020), pág. 6063, nota (276).

${ }^{13}$ Por todos, Rodrigo Bercovitz (2017), pág. 171.

${ }^{14}$ Por todos, Rodrigo Bercovitz (2017), págs. 164 y 165.

15 STJUE, 5a , 11.8.2020, asunto C-833/18, E. Juhász (Ponente), "SI y Brompton Bicycle Ltd c. Chedech/Get2Get" (ECLI: EU:C:2020:461), aptdo. (33).

${ }^{16}$ SSTJUE, 3a, 22.12 .2010 , asunto C-393/09, G. Arestis (Ponente), "Bezpečností softwarová asociace c. Ministerstvo kultury" (ECLI: EU:2010:816), aptdos. (48) y (49), Gran Sala, 13.11.2018, asunto C-310/17, M. Vilaras (Ponente), “Levola Hengelo BV c. Smilde Foods BV” (ECLI: EU:C:2018:899), aptdos. (27) y (30) a (33).

${ }^{17}$ SSTJUE, Gran Sala, 13.11.2018, asunto C-310/17, M. Vilaras (Ponente), "Levola Hengelo BV c. Smilde Foods BV" (ECLI: EU:C:2018:899), aptdos. (36) y (37); 3ª , 12.9.2019, asunto C-683/17, J. Malenovský (Ponente), "Cofemel - Sociedade de Vestuário, S.A. c. G-Star Raw CV” (ECLI: EU:C:2019:721), aptdo. (29), $5^{\mathrm{a}}$, 11.8.2020, asunto C-833/18, E. Juhász (Ponente), "SI y Brompton Bicycle Ltd c. Chedech/Get2Get" (ECLI: EU:C:2020:461), aptdo. (22).
} 
ingenio humano perteneciente al ámbito de la literatura, el arte o la ciencia o, si cuenta con el necesario reconocimiento legal, a un ámbito de otra naturaleza.

Las creaciones publicitarias se encuentran en nuestro ordenamiento en este segundo grupo de creaciones protegibles, y lo están por cierto desde la primera ley especial de la publicidad. Así, el derogado art. 70 de la Ley 61/1964, de 11 de junio, por la que se aprueba el Estatuto de la Publicidad dispuso que, "(s)in perjuicio de que las creaciones intelectuales o las invenciones que resulten de cualquier actividad publicitaria puedan gozar de los derechos de propiedad intelectual o industrial, las ideas publicitarias que posean la condición de novedad u originalidad atribuirán a su autor el derecho a perseguir cualquier posible imitación o a prohibir su utilización para fines distintos de los pactados". Por su parte, el vigente art. 21 I de la LGP establece sobre este extremo que "(l)as creaciones publicitarias podrán gozar de los derechos de propiedad industrial o intelectual cuando reúnan los requisitos exigidos por las disposiciones vigentes”, lo que a mi juicio completan, en primer término, el art. 20 de la LGP, según el cual “(c)ontrato de creación publicitaria es aquél por el que, a cambio de una contraprestación, una persona física o jurídica se obliga en favor de un anunciante o agencia a idear y elaborar un proyecto de campaña publicitaria, una parte de la misma o cualquier otro elemento publicitario"; y, en segundo término, el inciso primero del art. 14 de la LGP, a cuyo tenor "(e)l anunciante deberá abstenerse de utilizar para fines distintos de los pactados cualquier idea, información o material publicitario suministrado por la agencia...”. En fin, la definición de publicidad relevante en esta materia se encuentra en el art. 7 de la LGP, según el cual "(l)os contratos publicitarios se regirán por las normas contenidas en el presente Título, y en su defecto por las reglas generales del Derecho Común. Lo dispuesto en el mismo será de aplicación a todos los contratos publicitarios, aun cuando versen sobre actividades publicitarias no comprendidas en el artículo 2", por lo que la creación publicitaria protegible por medio de derecho de autor no solo integra la publicidad comercial del art. 2 de la LGP, sino también la institucional de los arts. 1 a 3 de la Ley 25/2005, de 29 de diciembre, de Publicidad y Comunicación Institucional, y la propaganda política, como es la electoral de los arts. 53 y concordantes de la Ley Orgánica 5/1985, de 19 de junio, del Régimen Electoral General, caracterizadas la primera y la última por tener un discurso persuasivo, sea sobre cuestiones de carácter comercial, sea sobre cuestiones de índole partidista, y la segunda, por tener un discurso informativo sobre cuestiones de interés general.

\section{Creaciones publicitarias objeto de derecho de autor}

\subsection{Creación publicitaria, discurso publicitario y transversalidad de su expresión}

En nuestro sistema de protección jurídica de la propiedad intelectual, las creaciones publicitarias tienen la consideración de creaciones intelectuales distintas de las obras literarias, artísticas o científicas. En efecto, el reconocimiento de que las creaciones publicitarias pueden protegerse mediante derecho de autor en una ley (la LGP) que se aprobó un año después que la ley (la LPI) que estableció una categorización de obras protegibles en la que no encuentra fácil acomodo la creación publicitaria, tratamiento que se ha mantenido en las sucesivas reformas de una y otra ley, solo puede significar que estas creaciones son cosa distinta de una obra audiovisual, una obra fotográfica, una obra literaria, una obra musical o, en general, una obra de las del art. 10.1 de la 
LPI ${ }^{18}$. Y lo mismo vale, ajustado lo que necesite ajustarse, respecto de la LPI de 1879 y el EP de 1964. Así lo confirma, además, el tratamiento positivo dado a esta cuestión en el art. 21 I de la LGP, que, tras reconocer la protegibilidad de estas creaciones mediante derechos de propiedad intelectual, remite a la LPI solo la determinación de los requisitos exigidos para que, en cada caso, se reconozca su protección (e implícitamente, claro está, la determinación de todos los demás aspectos del régimen jurídico de esa protección). Dicho en otros términos, la remisión del art. 21 I de la LGP a la LPI en esta materia no alcanza a la determinación de las categorías de obras protegibles mediante derecho de autor, precisamente porque, en relación con las creaciones publicitarias, esa determinación se halla en la norma publicitaria.

De otro modo, el art. 21 I de la LGP sería superfluo. Descartado que la utilidad de la creación intelectual impida que sea objeto de derecho de autor, ninguna necesidad existía de establecer el ahora art. 21 I de la LGP a fin de proteger mediante derecho de autor una película publicitaria o un spot televisivo, un jingle o tema musical publicitario, una fotografía o dibujo de un anuncio gráfico, un eslogan o fórmula publicitaria, o un texto publicitario más complejo, puesto que la naturaleza de estas creaciones intelectuales es, a todas luces y según proceda, la de una obra audiovisual, musical, fotográfica, plástica o literaria. Desde este punto de vista, las creaciones publicitarias se caracterizan por la transversalidad de su naturaleza expresiva que -frente a las obras literarias, artísticas o científicas - les presta precisamente su condición de publicidad y, en particular, su condición de vehículo de una comunicación dirigida a persuadir o informar a sus destinatarios, cuya esencia radica en su función, en la forma y medios con los que, por ejemplo, se impulsa su decisión de compra o simpatía por una propuesta política y cuyo valor social radica en su eficacia para conseguirlo, lo que no depende tanto de la expresión como de la sustancia, del contenido del discurso y de los recursos puestos a su servicio. Esto es, la creación publicitaria genuina es ese discurso publicitario y los recursos que concretan, estructuran, ordenan e interrelacionan sus elementos, cualquiera que sea la clase de material publicitario en que encuentren expresión (audiovisual, radiofónico, fotográfico, etc.).

En resumen, el silencio del art. 10.1 de la LPI respecto de las creaciones publicitarias no es un olvido que vino a reparar el art. 21 I de la LGP, sino el reconocimiento de que, en este caso, la creación intelectual es cosa distinta de las obras literarias, artísticas o científicas. En particular, lo es -como queda dicho- el discurso publicitario, esto es, el mensaje dirigido a persuadir o informar y los recursos de contenido (argumentales) y forma (estructura, orden e interrelación) mediante los que se presenta y desarrolla cualquiera que sea la clase de lenguaje expresivo escogida (escrito, audiovisual, musical, fotográfico, etc.), a capturar la atención del público objetivo e influir en sus preferencias y conducta, sea en relación con la oferta de un producto o servicio hecha mediante publicidad, sea en relación con la oferta política impulsada por la propaganda, sea en relación con los datos que transmite la publicidad institucional (arg. ex art. 7 LGP). A continuación se expondrá con algún detalle los fundamentos de esta tesis acerca del objeto de la creación publicitaria como categoría singular de creación protegida por medio de derecho de autor y sus implicaciones en relación con el alcance de esa protección.

\subsection{Objeto de la creación publicitaria}

\footnotetext{
${ }^{18}$ Se evita así la dificultad afrontada para insertar las creaciones publicitarias en los ordenamientos que solo contemplan que sean objeto de derecho de autor las obras literarias, artísticas o científicas, como sucede en Alemania: Gerhard SCHRICKER (1996), pág. 825.
} 
Para determinar el objeto de la creación publicitaria y los contornos que la delimitan como bien protegido por medio de derecho de autor es obligado, por claras razones sistemáticas, poner en relación el art. 21 de la LGP con su art. 20. De la lectura conjunta de estos preceptos se sigue que las creaciones publicitarias del art. 21 I de la LGP son el objeto de la prestación que los creativos se obligan a realizar por virtud del contrato de creación publicitaria del art. 20 de la LGP, que determina la tareas que deben realizar ("idear y elaborar") y el resultado, lo ideado y elaborado, que debe obtenerse y entregarse ("un proyecto de campaña publicitaria, una parte de la misma o cualquier otro elemento publicitario"), que algún autor ha designado, de forma resumida, como "proyecto publicitario" ${ }^{19}$ y al que, siguiendo los usos del sector, denominaré en adelante "propuesta creativa".

Así queda planteada la hipótesis que antes avancé y establecido un extremo esencial para la definición de la creación publicitaria como objeto de propiedad intelectual; a saber: la creación publicitaria, a la que se refiere la LGP, es el proyecto de comunicación publicitaria ideado y elaborado por los creativos, sus partes y su sustancia, y no en cambio el conjunto acabado (en condiciones de ser difundido) de piezas publicitarias interrelacionadas que forman una campaña publicitaria o una parte de una campaña, ni tampoco la pieza publicitaria individual y acabada, esto es, la fotografía que se expone en una valla, el spot televisivo que se emite, el jingle que se radiodifunde como parte de una cuña, la película publicitaria que se proyecta en un cine, el banner que se pone a disposición de los usuarios de Internet en una página web, etc.

Seguramente, esta lectura no encuentra un respaldo evidente en la determinación legal del objeto de las prestaciones comprometidas por los creativos según el art. 20 de la LGP por dos razones. De una parte, la construcción gramatical de la norma no es tan clara como debería haber sido, en el sentido de que el objeto de la prestación (lo comprometido como ideado y elaborado) es un proyecto - de una campaña, de una parte de una campaña o de un elemento publicitario cualquiera-, y no, como podría sugerir la letra de la norma, el proyecto de una campaña, una parte acabada de una campaña o un elemento publicitario ya producido, aunque la primera lectura, que aquí se defiende, es más acertada tanto lógicamente (pues no se acierta a ver por qué el objeto de la creación si se refiere a una campaña debe ser un proyecto, y si es un elemento publicitario debe ser, por ejemplo, un anuncio acabado y en condiciones de ser difundido) como sistemáticamente (pues la producción del material publicitario es una prestación distinta de la creación tanto en el proceso generalmente seguido para la ejecución de un encargo publicitario como en las relaciones que entre sí guardan los contratos de publicidad y de creación publicitaria). Y, de otra parte y como ha apuntado algún autor, la noción de creación como prestación contractual que comprende tanto la tarea de idear como la de elaborar sugeriría que el creativo se obliga a entregar una campaña, parte de campaña o elemento publicitario ya producido, acabado y en condiciones de ser difundido ${ }^{20}$, aunque parece más acertado, como aquí se propone, desgajar las tareas de idear y elaborar entre sí, como prestación dual y separable propia del creativo, y respecto de la producción, como prestación propia de la agencia.

En particular, la posición defendida (la creación publicitaria es funcionalmente un proyecto o propuesta) encuentra apoyo tanto en la secuencia de actuaciones que típicamente se suceden desde el encargo de la publicidad hasta su efectiva difusión, esto es, "el proceso publicitario",

\footnotetext{
${ }^{19}$ José M. ${ }^{\text {a }}$ DE LA CUESTA (2002), pág. 307.

${ }^{20}$ Luis A. MARCo ArCALÁ (2014), págs. 2093 y 2094.
} 
como en la práctica contractual del sector $\mathrm{y}$, especialmente, en la configuración sistemáticamente cabal del objeto y contenido del contrato de publicidad. Veámoslo.

\section{a. Creación publicitaria y proceso publicitario}

Para determinar en qué consiste la aportación comprometida y en su virtud la creación ideada y elaborada por el creativo, se debe rastrear el iter de generación de una campaña, de parte de la campaña o de un elemento publicitario, desde la decisión de encargar su realización hasta su finalización material, esto es, hasta que está acabado y presto para ser difundido (el "proceso publicitario" ${ }^{21}$. A continuación solo se hace referencia al proceso publicitario comercial, en el bien entendido de que puede trasladarse mutatis mutandis a la publicidad institucional y a la propaganda.

El proceso publicitario comienza con el llamado briefing de marketing. En este paso, el anunciante indica a la agencia de publicidad típicamente el producto o servicio objeto de la publicidad en que está interesado, el objetivo buscado con ella (incremento de ventas, lanzamiento, promoción de ventas, recuerdo, ganancia de notoriedad, asociación a emociones o sentimientos, captación de nuevos clientes, etc.), el círculo de destinatarios y su segmentación, el mensaje de la campaña y, en fin, los medios de difusión que considera apropiados.

Al briefing de marketing sigue la etapa de planificación que efectúa la agencia de publicidad (aunque no es infrecuente que los grandes anunciantes que cuentan con departamentos de publicidad también se hagan cargo de su preparación) y concluye con el llamado contrabriefing briefing publicitario o propuesta publicitaria, que en esencia es una respuesta al problema de marketing que deja planteado el briefing inicial del anunciante. En particular, el briefing o propuesta publicitaria es un resumen de la campaña o del elemento publicitario que se entiende adecuado para atender al requerimiento propuesto por el anunciante en su briefing de marketing y, de forma usual, contiene una definición de sus objetivos concretos, público destinatario, tono de la comunicación, seguimiento, presupuesto y estrategia creativa. Con esta última, se fijan el eje o ejes de la campaña o elemento publicitario, su mensaje central (más novedoso, más duradero, más económico, más exclusivo, etc.) y su tono (aspiracional, testimonial, objetivo, práctico, etc.), así como los medios de difusión y el cronograma de los trabajos pendientes hasta la finalización de la producción de la campaña o anuncio y de su difusión a través de los distintos medios en cada caso considerados.

Cerrada la propuesta publicitaria y obtenido el visto bueno del anunciante, entran en escena los creativos publicitarios. A partir del briefing o propuesta publicitaria, los creativos conciben y preparan la llamada propuesta creativa, que comprende el concepto creativo (o descripción de los elementos fundamentales y característicos del discurso publicitario y recursos asociados a la pieza o piezas publicitarias objeto del encargo recibido por el creativo) y la creatividad (presentación en borrador de la ejecución del concepto publicitario, ajustada a la forma de expresión del caso), cuya última versión, revisada en función de las observaciones del comitente directo o indirecto (el anunciante o la agencia), servirá de base y guía para la producción de las piezas de la campaña publicitaria o parte de ella o para la producción de los elementos publicitarios individuales encomendados.

${ }^{21}$ Cfr. Migel A. Furones (1980), págs. 32 y 33, y M. a Ángeles GonZÁlez Lobo y M. ${ }^{a}$ Dolores Prieto Del PinO (2009), capítulo VI (edición electrónica sin paginar). 
Esta producción es acometida por los "estudios" o productores (que pueden ser departamentos de las agencias o de los propios anunciantes). En esta etapa todavía se hacen ajustes de forma (por lo general) que quedan incorporados a la pieza final, que se corresponde con lo que en publicidad gráfica se ha denominado tradicionalmente "arte final", expresión que se utiliza también para referirse a lo que en la publicidad de radio y televisión se ha denominado "copia de emisión", actualmente archivos digitales en formatos y otras condiciones técnicas que permiten su reproducción (publicidad gráfica), su emisión (publicidad televisiva y radiofónica), su proyección (publicidad en cine), etc.

\section{b. $\quad$ Creación publicitaria y objeto del contrato de creación publicitaria}

La secuencia y ordenación de actuaciones que compone el proceso publicitario y, en particular, el contenido y objeto de la prestación asumida por cada uno de los actores de ese proceso se corresponden con la práctica contractual más consolidada en este sector, recogida en el Contrato Tipo de Publicidad de la Asociación Española de Anunciantes y la Asociación Española de Agencias de Publicidad ${ }^{22}$. Como es de ver en sus definiciones y en sus estipulaciones sobre los servicios de la agencia, el resultado del trabajo de los creativos (sean empleados de la agencia, sean terceros contratados al efecto) es una propuesta (que he denominado "propuesta creativa") conceptual (que he denominado "concepto publicitario") y expresiva presentada en forma de boceto u otro medio de expresión resumida (que he denominado "creatividad" ${ }^{23}$ ), a la que sigue, ya ejecutada por otros y supervisada por la agencia, la realización o producción del material publicitario en condiciones de ser difundido (lo que he denominado "artes finales" y se define en el Contrato Tipo como "las obras audiovisuales y gráficas, así como todas las partes componentes de los mismos que constituyen los mensajes publicitarios de las campañas”).

Este planteamiento se ajusta, además, al lugar que, en la interpretación sistemáticamente más acerada, posee la creación en la gestación de una campaña o un anuncio según la LGP y, en particular, en la definición de las prestaciones objeto del contrato de publicidad y su diferenciación y relación con las que lo son del contrato de creación publicitaria. En efecto, por virtud del contrato de publicidad la agencia compromete "la ejecución de publicidad y la creación, preparación o programación de la misma" (art. 13 I LGP), donde la creación de la publicidad es la prestación propia del contrato de creación (arg. ex art. 13 II LGP) y consiste, como se ha visto, en "idear y elaborar (por el creativo) un proyecto de campaña publicitaria, una parte de la misma o cualquier elemento publicitario" (art. 20 LGP), así como en el conjunto de actuaciones de coordinación y supervisión que se revelen precisas para la realización efectiva de esas tareas de idear y elaborar ${ }^{24}$. Salta a la vista que en este contexto ejecución y creación de la publicidad son cosas distintas, competen a sujetos distintos y tienen objetos diferentes; en particular, la ejecución es prestación propia del contrato de publicidad que versa sobre la publicidad en el sentido de pieza acabada y en condiciones de ser difundida, mientras que el idear y elaborar del contrato de creación publicitaria versan sobre un proyecto. Esto es, la ejecución de la publicidad comprende, como parte de la puesta en práctica de la publicidad y entre otras actuaciones, la producción del material publicitario que compone una campaña publicitaria, entera o una parte

\footnotetext{
${ }^{22}$ https://creatividadtransformadora.es/wp-content/uploads/2014/09/CONTRATO-TIPO.pdf.

${ }^{23}$ Expresión de la que también se hace eco en este contexto (objeto de la prestación contractual del creativo publicitario) José M. ${ }^{a}$ DE LA CUESTA (2002), pág. 307.

${ }^{24}$ En esta línea se orienta Carmen GARCíA PéreZ (2009), págs. 337 y 338.
} 
de ella, o la producción de un elemento publicitario, como un anuncio u otro vehículo adecuado para efectuar una comunicación persuasiva o informativa (como por ejemplo un gadget promocional) o parte de él (como por ejemplo el jingle de una cuña radiofónica) ${ }^{25}$. En cambio, la creación de la publicidad consiste, como prestación, en idear y elaborar la propuesta creativa, formada por el concepto creativo y la creatividad, que, como resultado de la prestación, sirve de base y guía para producir el material publicitario acabado. En particular, la propuesta creativa presenta, mediante su descripción y su ejecución de prueba, la concepción publicitaria ideada para el caso, el discurso o mensaje publicitario y los recursos de contenido y forma de que se vale, y en este sentido determina los materiales o medios publicitarios que forman una campaña o una parte de ella, así como las relaciones que guardan entre sí, o los que forman un concreto elemento publicitario, incluido su formato o lenguaje expresivo. Así las cosas, en la relación sistemática que guardan entre sí como objeto de los contratos publicitarios, la creación publicitaria es precisamente el resultado inmaterial de idear el concepto creativo y el resultado material de su elaboración mediante la incorporación de lo ideado a un borrador, que es el entregable que como prestación característica de un contrato de obra como es el de creación publicitaria- el creativo se obliga a realizar y entregar al comitente (por regla general, una agencia de publicidad) para que, tras su revisión y validación final por el comitente y, si no lo es, el anunciante, se proceda a la producción del arte final.

En suma, la creación publicitaria a la que el art. 21 I de la LGP reconoce la naturaleza de objeto protegible por medio de derecho de autor es previa a la producción de la publicidad, es el resultado creativo de idear ${ }^{26}$, que, a partir de la propuesta que lo expresa, se traslada a la campaña o al anuncio, por lo que como creación -conviene insistir- es distinta de la obra musical, audiovisual, musical, etc., que es o integra el anuncio, y más en particular es el resultado creativo que gobierna, guía y pauta la realización o producción de la campaña, toda o parte de ella, y pieza publicitaria acabada, lista para difundirse.

\section{c. Creación publicitaria, propuesta creativa, concepto publicitario, creatividad...}

El grueso de la creación publicitaria como resultado de un esfuerzo intelectual encaminado a dar respuesta (mediante un discurso y recursos persuasivos o informativos correspondientes) a la concreta formulación del problema publicitario planteado por el anunciante se halla, por lo tanto, en la propuesta creativa. Esta se articula generalmente en torno a dos elementos que típicamente se generan de forma sucesiva, el uno a partir del otro: el "concepto publicitario" y la "creatividad".

El concepto publicitario es la formulación escueta y, en general, revestida de un innegable grado de abstracción del discurso y recursos publicitarios que configurarán la campaña, parte de la campaña o elemento publicitario cuyo proyecto ha sido encomendado a los creativos. Comúnmente, consiste en la presentación de lo esencial del mensaje publicitario o alegación que debe captar la atención del destinatario y, según los casos, formar sus preferencias sobre lo ofrecido o su conocimiento de la cuestión abordada, del plan de desarrollo de ese mensaje, de la

\footnotetext{
${ }^{25}$ Un apunte en este sentido ofrece Carmen GARCíA PÉREZ (2009), pág. 342.

${ }^{26}$ En esta línea ya José M. ${ }^{a}$ DE LA CUESTA (2002), págs. 97, 100, aunque a renglón seguido de este último pasaje parecería negar que el resultado de idear, que considera genuina creación publicitaria, no estaría protegido por derecho de autor (pág. 100).
} 
elección y disposición de sus elementos o recursos de contenido y forma, y, en su caso, de la relación que entre sí guardan sus respectivas piezas.

Por su parte, la creatividad es la traslación imperfecta y aproximada (en borrador) del concepto publicitario, ya desarrollado, al medio expresivo que corresponda, con la finalidad última de que el anunciante se forme un juicio cabal sobre el resultado creativo y, en particular, la configuración del discurso publicitario y sus recursos, lo valide y, en su caso en forma de nueva versión, sirva de pauta para la producción de las artes finales que correspondan. La creatividad tiene distinta naturaleza expresiva según sea uno u otro el medio de difusión considerado: un script (descripción verbal de contenido), storyboard (sucesión de viñetas que representan las escenas del anuncio), animatic (animación digital de las escenas del anuncio) o incluso un video mood (storyboard filmado o animado) si se trata de una pieza publicitaria audiovisual, un boceto si se trata de una pieza gráfica, una maqueta si se trata de una pieza radiofónica, etc.

A partir de la propuesta creativa y, en particular, de la creatividad se producen -como se ha dicho- las artes finales, esto es, las piezas publicitarias acabadas y en condiciones de ser difundidas, en su caso previa obtención de las copias precisas para ello, a la que se traslada el concepto publicitario.

No parece dudoso, en suma, que las creaciones publicitarias genuinas, aquellas creaciones intelectuales que pueden ser protegidas por medio de derecho de autor según el art. 21 I de la LGP, porque no tienen cabida natural entre las obras literarias, artísticas o científicas del art. 10.1 de la LPI, son la propuesta creativa y las creaciones que la componen, a saber: el concepto publicitario, incluida la descripción de su desarrollo, y la creatividad, sin perjuicio de que, como es frecuente, en la fase de producción del arte final se realicen aportaciones creativas que completen, afinen o modifiquen la propuesta creativa, en el bien entendido de que, por regla general, estas aportaciones incidirán en los aspectos expresivos formales, y no en el discurso publicitario y sus recursos característicos.

\section{d. (sigue) ... y la sustancia de todo ello: las ideas publicitarias}

Pero tampoco parece dudoso que si esta fuera la única determinación con la que concluyera la consideración de las creaciones publicitarias como creaciones protegibles por medio de derecho de autor, el resultado alcanzado adolecería de cierto formalismo, que en última instancia podría reducir la aportación intelectual protegible que encarnan (el discurso publicitario y los recursos asociados ideados por los creativos) a la concreta expresión escrita, gráfica, etc., que tienen en el borrador en que se presentan para el visto bueno del comitente.

Este reduccionismo sería desacertado, porque seguiría dando la espalda a la realidad, que sitúa la esencia de la creación publicitaria en las ideas (discurso publicitario y recursos correspondientes) no por sí mismas consideradas, sino en cuanto se expresan ${ }^{27}$ inicialmente en el concepto publicitario y la creatividad, de donde pasan a expresarse en el material publicitario, en el que son reconocibles por sus elementos fundamentales y característicos, circunstancia que permite su incorporación a otros materiales publicitarios formalmente diversos, que es justamente la razón de ser y explica la oportunidad de su protección jurídica (vide infra [4]).

\footnotetext{
${ }^{27}$ Sobre la vigencia de la exigencia de expresión de las ideas publicitarias para acceder a su protección por medio de derecho de autor, Gerhard SCHRICKER (1996), pág. 825.
} 
Y porque daría la espalda asimismo a dos datos decisivos proporcionados por el tratamiento positivo que merecen las creaciones publicitarias. El primer dato positivo es la consideración legal de que la propuesta publicitaria hecha por el creativo, cuya aportación intelectual reside como se ha dicho- en el concepto publicitario y la creatividad, es el resultado de una prestación legalmente definida como "idear y elaborar", en cuya dualidad material y distinta naturaleza han reparado acertadamente algunos autores ${ }^{28}$, sin perjuicio de que puedan ser ejecutadas por un mismo sujeto y de que en todo caso la entrega de la obra contratada (propuesta creativa) exija su incorporación a un soporte adecuado ${ }^{29}$. Así, la idea expresada en la propuesta creativa (afincada en el concepto publicitario) y su elaboración (concretada en la creatividad) son resultados diferenciados de las prestaciones de idear y elaborar. De ahí que, en efecto, la creación publicitaria sea también, sobre todo, la idea que alienta y define los elementos fundamentales y característicos de una comunicación comercial, política o institucional (lo que he denominado "discurso publicitario y recursos asociados o correspondientes"), que preceden a su forma de expresión y son separables de ella (individualizables y reconocibles desligados de ella), a la que sigue su elaboración en borrador (lo que he denominado creatividad), para completar la propuesta creativa con su respectiva descripción y exposición justificada de su adecuación a lo encomendado o, lo que es lo mismo, de su idoneidad para responder al problema de marketing planteado por el anunciante. Se advierte, por tanto, que "idear" es en este contexto prestación dotada de autonomía (art. 20 LGP) y que existe una conexión sustantiva y sistemática entre el objeto de esa prestación (lo ideado, que es el discurso publicitario que se concreta esencialmente en el concepto publicitario y se presenta en la creatividad y que, materialmente, encierra en sí las claves de su éxito, de su capacidad de producir el efecto persuasivo o informativo al que sirve) y la condición de creación publicitaria que se proclama protegida mediante propiedad intelectual (art. 21 I LGP), que se proyecta sobre la concepción de la comunicación publicitaria y, en particular, sobre la determinación de sus recursos, su naturaleza o clase de expresión, su secuencia y ordenación, su disposición interna, sus relaciones, etc.

El segundo dato positivo es el explícito reconocimiento de una exclusiva sobre estas ideas, expresada en la prohibición que se impone al anunciante de utilizar "cualquier idea" que le proporcione la agencia de publicidad (en cuanto le corresponde efectuar, por sí o por otro, la creación publicitaria [art. 13 LGP]) para fines distintos de los pactados (art. 14 inciso primero LGP). Visto el tenor legal y el contexto, no existe ninguna razón convincente para identificar ideas con secretos empresariales, como se ha hecho seguramente para no caer en contradicción con la negativa a protegerlas mediante derecho de autor. Si así fuera, la misma prohibición pesaría sobre la agencia en relación con las ideas proporcionadas por el anunciante mediante el briefing de marketing (por regla general más rico en secretos empresariales que la propuesta creativa), pero el art. 14 de la LGP guarda silencio al respecto en su inciso segundo. Antes bien, es evidente que la prohibición de utilizar las ideas del art. 14 inciso primero de la LGP encarna una prevención contra la explotación de la creación publicitaria en contra o más allá de los derechos concedidos contractualmente, incluso tras la difusión del material publicitario primeramente producido y, por ello, solo puede asentarse en que las ideas a las que se refiere, que no son otras que las que se generan con la actuación que conduce a la creación publicitaria ("idear"), son objeto de tutela jurídica, que en este contexto es, al menos, la que proporciona la legislación sobre propiedad intelectual (arg. ex arts. 14, 20 y 21 LGP).

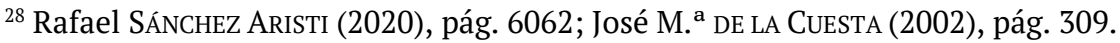

${ }^{29}$ José M. ${ }^{\mathrm{a}}$ DE LA CUESTA (2002), pág. 312.
} 


\subsection{Conformidad con la definición de obra según el Tribunal de Justicia de la Unión Europea}

Lo sostenido hasta aquí no entra en conflicto con la definición de obra como objeto de derecho de autor en la jurisprudencia del TJUE. Esta no es cuestión menor. En efecto, por una parte, la Directiva 2001/29/CE establece una armonización completa en los preceptos que se refieren al derecho de autor sobre las obras ${ }^{30} \mathrm{y}$, sobre ello, no consiente que la legislación interna proteja mediante derecho de autor creaciones que no sean obras en el sentido de la Directiva: "la protección asociada a los derechos de autor... está reservada a los [objetos] que merecen ser calificados de obras" ${ }^{31}$. Por otra parte, obra es a estos efectos un concepto de Derecho de la Unión y, como tal, objeto de la interpretación uniforme y autónoma que establezca el TJUE ${ }^{32}$. Así, las creaciones publicitarias del art. 21 I de la LGP, definidas como se ha propuesto, serán obras susceptibles de ser protegidas por medio de derecho de autor si tienen un objeto y naturaleza que permita encuadrarlas en la definición de obra de la jurisprudencia del TJUE; de otra forma, aquel precepto sería contrario a la Directiva 2001/29/CE 33 .

Desde esta perspectiva, no es dudoso que obra es una "creación intelectual" ${ }^{44}$. Y tampoco lo es que, dejando de lado - como debe ser- las adherencias de requisitos de protección que se integran en su definición, la creación intelectual protegible mediante derecho de autor se caracteriza, en un sentido negativo, por no ser una idea sin expresión, esto es, por no ser una idea en sí, puesto que "la protección del derecho de autor abarca las expresiones pero no las ideas... en $s^{\text {" }}{ }^{35}$, y se caracteriza asimismo, en un sentido positivo, por tener un "objeto identificable con suficiente precisión y objetividad" ${ }^{36}$ en el que no se confundan "la idea y la expresión" ${ }^{37}$. Esas creaciones intelectuales, en cambio, no se caracterizan ni limitan, ni en la Directiva 2001/29/CE ni en la jurisprudencia que la interpreta, por ser de una concreta naturaleza expresiva, y en

30 STJUE, Gran Sala, 29.7.2019, asunto C-469/17, M. Ilešič (Ponente), “Funke Medien NRW GmbH c. Bundesrepublik Detschland” (ECLI: EU:C:2019:623), aptdos. (35) a (38).

${ }^{31}$ STJUE, $3^{\text {a }}$, 12.9.2019, asunto C-683/17, J. Malenovský (Ponente), “Cofemel - Sociedade de Vestuário, S.A. c. G-Star Raw CV” (ECLI: EU:C:2019:721), aptdo. (50) in fine.

32 SSTJUE, Gran Sala, 13.11.2018, asunto C-310/17 , M. Vilaras (Ponente), “Levola Hengelo BV c. Smilde Foods BV” (ECLI: EU:C:2018:899), aptdo. (33); 3ª 12.9.2019, asunto C-683/17 J. Malenovský (Ponente), “Cofemel - Sociedade de Vestuário, S.A. c. G-Star Raw CV” (ECLI: EU:C:2019:721), aptdo. (29); 4 ${ }^{\text {a }}$ 16.7.2009, asunto C-5/08 J. Malenovský (Ponente), “Infopaq International A/S contra Danske Dagblades Forening" (ECLI: EU:C:2009:465), aptdo. (27).

${ }^{33}$ STJUE, Gran Sala, 13.11.2018, asunto C-310/17 , M. Vilaras (Ponente), “Levola Hengelo BV c. Smilde Foods BV” (ECLI: EU:C:2018:899), aptdo. (45).

${ }^{34}$ SSTJUE, Gran Sala, 13.11.2018, asunto C-310/17 , M. Vilaras (Ponente), “Levola Hengelo BV c. Smilde Foods BV” (ECLI: EU:C:2018:899), aptdo. (37); y 3a , 12.9.2019, asunto C-683/17 J. Malenovský (Ponente), “Cofemel - Sociedade de Vestuário, S.A. c. G-Star Raw CV” (ECLI: EU:C:2019:721), aptdo. (29).

${ }^{35}$ STJUE, Gran Sala, 13.11.2018, asunto C-310/17 , M. Vilaras (Ponente), “Levola Hengelo BV c. Smilde Foods BV” (ECLI: EU:C:2018:899), aptdo. (39).

36 SSTJUE, Gran Sala, 13.11.2018, asunto C-310/17 , M. Vilaras (Ponente), “Levola Hengelo BV c. Smilde Foods BV” (ECLI: EU:C:2018:899), aptdo. (40), y 3a , 12.9.2019, asunto C-683/17 J. Malenovský (Ponente), “Cofemel - Sociedade de Vestuário, S.A. c. G-Star Raw CV” (ECLI: EU:C:2019:721), aptdo. (32).

37 SSTJUE, 5a , 11.8.2020, asunto C-833/18, E. Juhász (Ponente), “SI y Brompton Bicycle Ltd c. Chedech/Get2Get” (ECLI: EU:C:2020:461), aptdo. (27); 3a , 22.12.2010, asunto C-393/09, G. Arestis (Ponente), “Bezpečností softwarová asociace c. Ministerstvo kultury” (ECLI: EU:C:2010:816), aptdos. (48) y (49). 
particular por ser solo las de naturaleza literaria, artística (de hecho se descarta expresamente que la obra sea una creación intelectual caracterizada por elementos estéticos, porque ello requeriría "una identificación basada esencialmente en las sensaciones, intrínsecamente subjetivas, de la persona que percibe el objeto en cuestión [lo que] no cumple la exigencia requerida de precisión y objetividad" ${ }^{88}$ ) o científica.

La cuestión que queda planteada es, por lo tanto, si las creaciones publicitarias, entendidas en los términos expuestos, son creaciones intelectuales cuyo objeto es una idea en sí o si cuentan con un objeto que, por su expresión, puede identificarse de manera precisa y objetiva (aunque no tenga naturaleza literaria, artística o científica), condición que debe estimarse satisfecha si permiten a jueces y tribunales y otras autoridades involucradas en la defensa del derecho de autor y, en general, a los agentes económicos interesados conocer e identificar su objeto con la claridad y certeza que requiere un nivel razonable de seguridad jurídica y, por tanto, sin consideraciones subjetivas. Y la respuesta no es dudosa: nada en el objeto ni en la naturaleza de las creaciones publicitarias y, en particular, de la propuesta creativa y sus componentes (concepto publicitario y creatividad) impide que el discurso y los recursos publicitarios que presentan sean expresados de forma que quienes operan en el sector y quienes resuelven disputas en el sector estén en condiciones de determinarlos, reconocerlos, apreciar su singularidad y, en su caso, valerse de ellos para confeccionar otra campaña u otro elemento publicitario de los que sean y se reconozcan como elementos fundamentales y caracterizadores ${ }^{39}$.

De hecho, así lo prueban las resoluciones, antes recordadas, que han afirmado la protegibilidad e infracción de los formatos televisivos y los argumentos o que han caracterizado y afirmado la existencia de la transformación de un guion cinematográfico. Y ello, además, encuentra pleno respaldo en la posición del TJUE, claramente afirmativa de la protección de las creaciones intelectuales (con independencia de la clase de su forma de expresión) que, como los conceptos publicitarios y las creatividades, están indicadas para servir de material y patrón de confección de una obra literaria, artística o científica, del modo en que, en particular, tiene dicho expresa y precisamente respecto de "los trabajos preparatorios de concepción que pueden llevar... a la creación ulterior de tal programa" de ordenador ${ }^{40}$, cuya proximidad a las creaciones publicitaras es más que evidente.

Siendo esto así, conceptos publicitarios, creatividades y propuestas creativas y especialmente las ideas o discurso publicitario que las expresa y los recursos que las presentan en cuanto son sus elementos fundamentales y caracterizadores, en cuanto las hacen reconocibles, no están excluidos de la noción de obra de la jurisprudencia del TJUE y, en consecuencia, nada impide reconocerlos como creaciones intelectuales objeto de derecho de autor, del modo en que, según vengo argumentando, hace el art. 21 I de la LGP.

\footnotetext{
${ }^{38}$ SSTJUE, Gran Sala, 13.11.2018, asunto C-310/17 , M. Vilaras (Ponente), "Levola Hengelo BV c. Smilde Foods BV” (ECLI: EU:C:2018:899), aptdo. (42), y 3a , 12.9.2019, asunto C-683/17 J. Malenovský (Ponente), “Cofemel - Sociedade de Vestuário, S.A. c. G-Star Raw CV" (ECLI: EU:C:2019:721), aptdo. (34).

${ }^{39}$ STJUE, $4^{\mathrm{a}}$, 16.7.2009, asunto C-5/08J. Malenovský (Ponente), "Infopaq International A/S contra Danske Dagblades Forening" (ECLI: EU:C:2009:465), aptdo. (47).

${ }^{40}$ SSTJUE, Gran Sala, 2.5.2012, asunto C-406/10, G. Arestis (Ponente), "SAS Institute Inc. contra World Programming Ltd” (ECLI:EU:C:2012:259), aptdo. (37), y asimismo STJUE, 3ª 22.12.2010, asunto C-393/09, G. Arestis (Ponente), "Bezpečností softwarová asociace c. Ministerstvo kultury” (ECLI: EU:C:2010:816), aptdos. (36) y (37).
} 


\section{Alcance de la protección de la creación publicitaria mediante derecho de autor}

Seguramente, la verdadera relevancia de la tesis aquí defendida acerca de las creaciones (propuesta creativa, concepto y creatividad, así como ideas que componen el discurso publicitario y los recursos de contenido y forma escogidos para su presentación) que merecen ser consideradas creaciones publicitarias protegibles por medio de derecho de autor reside en el alcance de su tutela. Y así se comprueba en cuanto se perfilan las realizaciones comprendidas en el ámbito objetivo sobre el que se extienden los derechos atribuidos al autor o autores de la creación publicitaria protegida.

No existe norma que aborde esta cuestión, como tampoco hay una norma general que la aborde en la LPI. Para su determinación habrá que estar a la singularidad de la naturaleza de las creaciones publicitarias como creaciones protegibles, a la que están vinculados los aspectos más característicos de las modalidades de explotación que pueda recibir. Bajo este aspecto, la singularidad de las creaciones publicitarias radica en su condición de creación precursora de otras. Esta condición se proyecta, por una parte, sobre la colección de piezas publicitarias que encarnarán la campaña publicitaria y sobre la forma en que se relacionarán y coordinarán las unas con las otras en la obra literaria, artística o, si acaso, científica que una vez producido constituirá el anuncio o elemento publicitario acabado y listo para su difusión, a las que traslada el discurso publicitario ideado y los recursos escogidos para su presentación y desarrollo. Y se proyecta, por otra parte, sobre las exigencias y retos que plantea su efectiva protección en atención a esta concreta condición de creación precursora de otras.

La condición de creación intelectual precursora, que no parte integrante, de una obra literaria, artística o científica no constituye, en realidad, ninguna novedad sustantiva ni sistemática en nuestro ordenamiento sobre derecho de autor. En efecto, el catálogo de obras protegibles del art. 10.1 de la LPI incluye creaciones que poseen esta misma condición, como son los ensayos o bocetos de las obras plásticas, los proyectos, maquetas y diseños de obras arquitectónicas y de ingeniería, como también lo hacen el art. 96.1 II inciso primero de la LPI, respecto de la documentación preparatoria de los programas de ordenador y, de forma implícita, los arts. $87 \mathrm{y}$ 88.2 de la LPI, respecto del argumento, adaptación y guion de las obras audiovisuales. En esta línea se orienta, por otra parte, el reconocimiento jurisprudencial de la protegibilidad mediante 
derecho de autor de los llamados formatos de televisión ${ }^{41}$, los argumentos ${ }^{42} \mathrm{o}$ los personajes de obras de ficción ${ }^{43}$.

Por su parte, las necesidades de protección o, para ser más próximo a la realidad, los intereses legítimos de los creativos publicitarios más típicamente comprometidos y necesitados de tutela coinciden asimismo con los que típicamente se presentan en la mayor parte de estas creaciones precursoras expresamente incluidas entre las obras protegibles, especialmente los argumentos, guiones y formatos de televisión ${ }^{44}$. Como en ellos, la modalidad de explotación inconsentida que más intensamente compromete esos intereses no es la reproducción, esto es, la realización de copias totales o parciales de la pieza publicitaria en cuestión a partir de su soporte original o de otras copias del soporte original del concepto publicitario o de la creatividad, ni la distribución de esas copias ni la comunicación al público de copias o del original. Lo es la apropiación del concepto publicitario, de las ideas (de contenido y forma) que constituyen el resultado del esfuerzo intelectual, del genio del creativo publicitario, y se plasman en el discurso publicitario y en los recursos de que se vale, apropiación que acaece mediante su utilización no consentida para producir una campaña, una parte de ella o un elemento publicitario, que no necesita en absoluto de ejemplares del concepto publicitario ni de la creatividad, puesto que se deducen con facilidad de la contemplación de su ejecución consentida (del anuncio gráfico que contiene un dibujo o fotografía o del que contiene un eslogan, del spot publicitario que consta de la sucesión de imágenes y sonido, etc.) y a cuya prevención responde sin duda la prohibición de emplear las ideas creativas que pesa sobre el anunciante (art. 14 inciso primero LGP). En este sentido, la creación publicitaria se abstrae del anuncio como ejecución concreta de un concepto publicitario y obra acabada obtenida a partir de la guía que procura la creatividad, esto es y del modo en que apunté antes, se separa de la obra audiovisual que es la película publicitaria, de la obra fotográfica que es la fotografía publicitaria, etc., y naturalmente de las prestaciones relacionadas protegibles por medio de los derechos afines de la Directiva 2001/29/CE, como son por ejemplo las grabaciones audiovisuales en que se fijan las películas publicitarias o los fonogramas en que se fijan los jingles, para aproximarse a las ideas (que no identificarse con ellas) y, en sentido opuesto, descender hasta los elementos individualizados que las encarnan en lo que se viene denominado discurso publicitario y recursos de contenido y forma escogidos para su presentación.

Como en el caso del argumento, guion o formato de televisión, la explotación inconsentida de las creaciones publicitarias se presenta en la práctica bajo la forma de transformación (arts. $17 \mathrm{y}$

\footnotetext{
${ }^{41}$ SSTS, $1^{\text {a }}$, núm. 588/2014 de 22 de octubre, Magistrado Ponente: Rafael Sarazá Jimena, “A todo corazón” (ECLI: ES:TS:2014:4623), que define el formato precisamente como "conjunto de elementos técnicos e intelectuales destinados a la realización de un programa de televisión”, y núm. 792/2010 de 9 de diciembre, Magistrado Ponente: José Ramón Ferrándiz Gabriel, “La botica de la abuela” (ECLI: ES:TS:2010:7202), a las que se puede sumar la SAP Madrid, Civil 28 a 20.9.2016, Magistrado Ponente: Ángel Gago Peco, "Pasapalabra" (ECLI: ES:APM:2016:12100), confirmada, en los extremos recurridos solo relativos a la indemnización de daños y perjuicios, por STS, $1^{\text {a }}$, núm. 30 septiembre, Magistrado Ponente: Rafael Sarazá Jimena, "Pasapalabra" (ECLI: ES:TS:2019:2852). Entre los autores, Alfonso GonZÁlez GoZALo (2001), con otras citas.

${ }^{42}$ SAP Madrid, Civil 28a , 8.4.2011, Magistrado Ponente: María de los Ángeles Rodríguez Alique, “Corazones púrpuras" (ECLI: ES:APM:2011:2697).

${ }^{43}$ STS, $1^{\text {a }}$, núm. 663/1999 de 15 de julio, Magistrado Ponente: Alfonso Barcala Trillo-Figueroa, "Los Mundos de Yupi" (ECLI: ES:TS:1999:5135), y SAP Barcelona, Civil 15ª 2 28.5.2003, Magistrado Ponente: Jordi-Lluis Forgas Folch, "Lara Croft" (AC 2003\960).

${ }^{44}$ Gerhard SCHRICKER (1996), págs. 824 y 825.
} 
21 LPI). Esta modalidad de explotación se ha caracterizado recientemente, de forma clara y precisa, por referencia a la reconocibilidad de la obra preexistente en la obra derivada debida a la presencia de coincidencias esenciales en los contenidos (que la doctrina especializada ha relacionado comúnmente al ámbito de las ideas ${ }^{45}$ ) y, en particular, en los elementos conceptuales que articulan la creación preexistente (como son, predicados de un guion, la "concepción de las características de los personajes", "los hitos esenciales en torno a los cuales aparece vertebrado el relato" o los "elementos fundamentales de la historia que esta [la obra preexistente] relata"), y no en su expresión formal, aun cuando aquella incorpore otros elementos creativos y originales propios ("aportaciones sustanciales") también relacionados con los aspectos conceptuales ("la idiosincrasia y el diseño de las características singulares de los personajes") ${ }^{46}$.

Esta caracterización de lo protegible en una obra frente a su transformación, aplicada a nuestro caso, implica que, a pesar de la presencia de aportaciones sustanciales incorporadas en las artes finales con ocasión de su producción, las aportaciones intelectuales fundamentales de una creación publicitaria - aquellas que, como los hitos del relato o historia y las características o idiosincrasia de los personajes, articulan el discurso publicitario y le prestan individualidadadmiten formas de expresión diversas sin perder por ello su individualidad, configuran los elementos fundamentales del discurso publicitario y sus recursos, aquellos que hacen reconocible a una campaña publicitaria en otra anterior o a un elemento publicitario en otro anterior, y tienen expresión en la propuesta creativa en su conjunto, así como en la creatividad e incluso pueden hallarse, según sea su grado de desarrollo formal, en el concepto publicitario. En suma, los contenidos, esto es, las ideas o discurso publicitario y los recursos asociados que individualizan el concepto publicitario y la creatividad son la sustancia de la creación publicitaria y como tal son objeto de derecho de autor.

Sin perjuicio de ello, en cada caso habrá de comprobarse, como es lógico, si los recursos que se diga que encarnan la singularidad del discurso publicitario son identificables de forma clara, precisa y objetiva, lo que es tanto como preguntarse y comprobar si solo encarnan ideas en sí o si, por el contrario, las expresan de forma adecuada para realizar una campaña o un elemento publicitario que integren sus aportaciones creativas fundamentales y características, en los que también serán reconocibles a pesar de recibir una expresión formal distinta. La cuestión planteada no es desconocida en el ámbito del derecho de autor general. Se trata, en efecto, de deslindar entre la idea abstracta o genérica, que admite expresiones o ejecuciones formales tan alejadas como para no reconocer en unas a las otras y que no merece protección mediante derecho de autor, por una parte, y, por otra, la idea tratada, desarrollada y concretada formalmente hasta el punto de anticipar su expresión o ejecución, de guiar su concreción formal hasta un resultado previsible y reconocible como lo es sustancialmente en el original, que merece protección, como se ve en relación con una película publicitaria que se reconoce protegida por medio de derecho de autor, y su infracción resulta precisamente de la coincidencia del esquema general, configuración formal, personajes, etc., o más sencillamente de los recursos que componen e hilan el discurso publicitario ${ }^{47}$.

\footnotetext{
${ }^{45}$ Rafael SÁNCHEZ ARISTI (2000), págs. 27, 29, con otras referencias. Y especialmente sobre su protección mediante derecho de autor, Ulrich LOEWENHEIM (2020), § 2 UrhG, Rn. 78, 80.

46 SAP Madrid, Civil 28a , 19.10.2020, Magistrado Ponente: Pedro María Gómez Sánchez, "La reina de España” (ECLI:ES:APM:2020:12903).

${ }^{47}$ SAP Barcelona, Civil 15a , 25.2.2020, Magistrado Ponente: José María Fernández Seijo, “Dial Vision” (ECLI: ES:APB:2020:1094), en cuanto transcribe y confirma el razonamiento de la sentencia de instancia (JMer
} 
Las consecuencias de la redefinición del alcance de la protección jurídica de las creaciones publicitarias que se defiende y en particular su extensión a las ideas publicitarias en los términos que se han dicho no se hacen esperar. De lo dicho se sigue, en efecto, que la utilización de esas ideas o, si se prefiere, de los elementos fundamentales y caracterizadores del discurso publicitario y los recursos que las expresan no habrá de ser combatida como acto de competencia desleal y en particular de imitación u obstaculización desleal, que no es una tarea sencilla ${ }^{48}$, sino como acto de infracción de los derechos exclusivos conferidos por el derecho de autor, que posee sin duda un postulado más favorable a la protección, una base objetiva más sólida y una estructura más liviana. Un postulado más favorable a la protección, porque el punto de partida es la reserva de la explotación económica de la creación intelectual, este caso de las creaciones publicitarias, frente a la legitimidad de principio tanto de la interferencia concurrencial en la actividad de otro como, en particular, de la imitación. Una base más sólida, porque comprobar la presencia de los requisitos exigidos para que una creación intelectual tenga reconocida la condición de obra protegible por medio de derecho de autor es una operación típicamente más sencilla y segura que establecer la presencia de aquellos que debe tener una prestación (singularidad competitiva, implantación en el mercado, atesoramiento de reputación) o actividad (ventaja competitiva de la que se tiene la expectativa legítima de explotar sin interferencia de otro) para ser protegidas frente a la imitación o la obstaculización desleales. Y, en fin, una estructura más liviana, porque la actuación del derecho de autor exige menos condiciones para estimarse producida que las exigidas en materia de competencia desleal. En particular, la afirmación de que se ha cometido una infracción de la protección las ideas que residen y se expresan a través de la propuesta creativa y sus elementos no exige comprobar ninguna otra circunstancia distinta de la efectiva utilización de las ideas protegidas (de los elementos fundamentales y caracterizadores del discurso publicitario y sus recursos) en cualquier forma o modalidad de explotación comprendida entre los derechos económicos, como por el contrario se exige para afirmar la imitación desleal (que debe atender, por ejemplo, al modo en que se produce la imitación, a la concurrencia en el mercado de original e imitación y al momento en que se produce el aprovechamiento de la prestación imitada) o la obstaculización desleal (que debe atender a la injerencia en la posición competitiva y a las legítimas expectativas de aprovechamiento así como a la falta de justificación concurrencial).

\section{Aplicación del régimen jurídico general sobre derecho de autor}

En lo demás y por virtud de la remisión final del art. 21 I de la LGP, la protección jurídica de las creaciones publicitarias mediante derecho de autor queda sujeta al régimen establecido con carácter general en la LPI. Esta remisión se extiende, entre otros extremos, a los requisitos materiales que deben concurrir para merecer esa protección y la atribución de la titularidad de la protección como en relación con el contenido de esa protección, si bien respecto de esto último

núm. 2 de Barcelona): "Las similitudes con los anuncios referidos son muy elevadas, esas similitudes se producen en los mismos tiempos y la duración de los anuncios es muy similar, como lo es la estructura de los relatos que estructuran cada uno de los anuncios, con diálogos muy parecidos y mensajes casi idénticos. Son parecidas las actitudes de los personajes además del contexto, planos, las secuencias, los escenarios, iluminación, ángulos y la gama cromática, la velocidad y velocidad y los movimientos de la cámara”.

${ }^{48}$ Anxo TAтo (2017), págs. 32 a 39. 
se establece una norma especial, como es la presunción de cesión de los derechos de explotación (art. 21 II in fine LGP).

\subsection{Requisitos sustantivos para la efectiva protección de las creaciones publicitarias mediante derecho de autor}

Naturalmente, la comprobación de que la propuesta creativa y sus componentes tienen el grado de definición suficiente para guiar la realización de una obra que posea sus elementos o recursos fundamentales (que articulan el discurso publicitario) y en los que sean reconocibles de forma clara, precisa y objetiva, a pesar de la posible presencia de otras contribuciones creativas por regla general incorporadas en la etapa de ejecución, no es bastante para afirmar su protección mediante derecho de autor. Para ello es necesario que reúnan las condiciones o requisitos exigidos con carácter general para que una creación intelectual que por su naturaleza es protegible quede en efecto protegida, por lo que ahora interesa, mediante la atribución del derecho exclusivo a controlar su explotación, como son su condición de creación humana, original y expresada en un soporte tangible o intangible.

Ninguna especialidad presentan estos requisitos en el ámbito de las creaciones publicitarias, aunque no está de más recordar ahora la forma en que la originalidad, seguramente el factor crítico para su protección mediante esta modalidad de propiedad intelectual, ha sido perfilada por la jurisprudencia de la Unión. En particular, el TJUE concibe la originalidad como creación intelectual propia de su autor ${ }^{49}$ y, más en particular, como expresión de su genio y capacidad creativa ${ }^{50}$ que refleja su personalidad en la obra mediante decisiones libres y creativas ${ }^{51}$ que, de forma acumulada o alternativa, determinan la concepción de la creación, su ejecución o ambas ${ }^{52}$, pero también -lo que puede ser de especial relevancia en creaciones destinadas a servir a un fin práctico como es propio de la publicidad- en la forma de abordar la materia y el modo expresivo seleccionado ${ }^{53}$. La presencia de estas condiciones habrá de apreciarse caso por caso, y para ello habrá que tener en cuenta "todos los elementos del caso concreto, tal y como existían durante la concepción de ese objeto, independientemente de los factores exteriores y posteriores a la concepción de ese objeto" ${ }^{\prime 4}$. Al efecto es obligado dar especial relevancia precisamente a lo característico de la creación publicitaria, como es su naturaleza funcional, y en particular su finalidad persuasiva o institucional, su sustancia, condensada en el discurso publicitario y en los recursos de

\footnotetext{
${ }^{49}$ SSTJUE, Gran Sala, 13.11.2018, asunto C-310/17, M. Vilaras (Ponente), “Levola Hengelo BV c. Smilde Foods BV” (ECLI: EU:C:2018:899), aptdo. (36); 4ª 16.7.2009, asunto C-5/08J. Malenovský (Ponente), “Infopaq International A/S contra Danske Dagblades Forening” (ECLI: EU:C:2009:465), aptdo. (48).

50 STJUE. 5a ${ }^{\mathrm{a}}$ 11.8.2020, asunto C-833/18, E. Juhász (Ponente), "SI y Brompton Bicycle Ltd c. Chedech/Get2Get” (ECLI: EU:C:2020:461), aptdo. (34).

${ }^{51}$ STJUE, 3a , 12.9.2019, asunto C-683/17, M. Vilaras (Ponente), “Cofemel - Sociedade de Vestuário, S.A. c. G-Star Raw CV” (ECLI: EU:C:2019:721), aptdos. (30), (31) y (54).

${ }^{52}$ Implícito en STJUE, 5a, 11.8 .2020 , asunto C-833/18, E. Juhász (Ponente), “SI y Brompton Bicycle Ltd c. Chedech/Get2Get” (ECLI: EU:C:2020:461), aptdo. (37). Y, entre los autores, Rodrigo BeRCOVITZ (2017), pág. 162.

${ }^{53}$ STJUE, $4^{\text {a }}$, 16.7.2009, asunto C-5/08, G. Arestis (Ponente), “Infopaq International A/S contra Danske Dagblades Forening” (ECLI: EU:C:2009:465), aptdo. (44).

54 STJUE, 5a , 11.8.2020, asunto C-833/18, E. Juhász (Ponente), “SI y Brompton Bicycle Ltd c. Chedech/Get2Get” (ECLI: EU:C:2020:461), aptdo. (37).
} 
contenido y forma de que se vale para alcanzar los objetivos (persuasivos o institucionales) considerados $^{55}$.

Como se ve, la cuestión que, bajo este aspecto, suscita la protección de la creación publicitaria es un clásico en el temario de los problemas difíciles del derecho de autor, en el que viene a ocupar asiento al lado de la protección de los formatos de TV. Y, como sucede en estos casos, son más las ocasiones en que el conflicto se dirime negando la protección, por considerarse que la pretendida creación publicitaria reproducida sin autorización es una idea genérica o, al menos, no suficientemente perfilada desde un punto de vista formal ${ }^{56}$, aunque en no pocas ocasiones el razonamiento apunta sobre todo a la previa generalización del uso de la idea que inspira la pieza publicitaria imitada, desdibujándose así los lindes entre la negación general de la tutela de las ideas en sí y el rechazo particular de la protección de las elaboraciones formales de ideas que alcanzan la concreción necesaria para ser obras, pero carecen de la originalidad necesaria ${ }^{57}$.

\subsection{Atribución de la protección y presunción de cesión de derechos de explotación}

La atribución de la titularidad originaria de la protección jurídica de las creaciones publicitarias mediante derecho de autor sigue las reglas generales de la LPI, con las dos excepciones siguientes: la presunción de cesión exclusiva de los derechos de explotación sobre la creación publicitaria protegida al anunciante o a la agencia de publicidad que haya sido comitente en el contrato de creación publicitaria correspondiente, prevista en el art. 21 II de la LGP ${ }^{58}$, y la exclusión del reconocimiento de los derechos de remuneración propios de los autores de obras audiovisuales a los que lo sean de obras de esta clase que tengan carácter publicitario, establecida en el art. 90.6 in fine de la LPI.

La parquedad del tratamiento de esta materia no debe hacer pensar que sea una cuestión fácil. No lo es, en primer término, la determinación de la autoría y, con ello, la titularidad y convivencia de los derechos sobre las distintas concreciones que, como creación evolutiva en la que interviene una pluralidad de sujetos, tiene la creación publicitaria desde el concepto publicitario hasta el arte final, pero esta es cuestión que presenta puntos en común con aquellas obras que he denominado "precursoras" de otras obras y merece su propio estudio.

Y otro tanto ha de decirse de la presunción de cesión de derechos, que no es ciertamente la que subyace a la prevista para las obras colectivas (art. 8 LPI) ni la correspondiente a las creaciones asalariadas (art. 51 LPI), sino un supuesto de cesión de derechos sobre obra de encargo que, como es sabido, carece de una regulación general y del que conviene reparar en su limitación a los fines previstos en el contrato de creación publicitaria. Puesto este extremo en relación con lo que se ha dicho, no solo sobre los aspectos o elementos de la creación publicitaria protegidos por medio

\footnotetext{
${ }^{55}$ Un apunte en este sentido se encuentra en José M. ${ }^{a}$ DE LA CUESTA (2002), pág. 101.

${ }^{56}$ RJP, Sección Tercera, de 27 de diciembre de 2005, “Cranium/Party \& Co”, y otros pronunciamientos judiciales y resoluciones del Jurado de la Publicidad citados por Anxo TATo (2017), págs. 9 a 10.

${ }^{57}$ RJP, Sección Primera, de 20 de enero de 2003, “Danissimo”, y otros pronunciamientos judiciales y resoluciones del Jurado de la Publicidad citados por Anxo TAто (2017), págs. 6 a 7.

${ }^{58}$ Anxo TAтo (2017), págs. 13 a 16.
} 
de derecho de autor sino también sobre el alcance de esa protección y de forma singular el que tienen las ideas publicitarias que puedan trasladarse a las artes finales por medio de expresiones distintas, parece evidente que la omisión o la imprecisión de la determinación de los fines del contrato de creación publicitaria puede haber dejado en la carteta de derechos de los creativos un dominio considerable sobre la explotación de sus ideas. Pero esto también merece su propio estudio.

\section{Bibliografía}

Rodrigo BerCovitz (2017), “Art. 10.1”, en Rodrigo BerCovitz (coord.), Comentarios a la Ley de Propiedad Intelectual, $4{ }^{\mathrm{a}}$ ed., Tecnos, Madrid, págs. 159 y ss.

José M. ${ }^{a}$ DE LA Cuesta (2002), Curso de Derecho de la publicidad, EUNSA, Pamplona.

Carlos FERNÁNDEZ NOVOA (1989), “La protección jurídica de las creaciones y obras publicitarias”, en Estudios de Derecho de la publicidad. Homenaxe da Facultade de Dereito ó autor Dr. Carlos Fernández-Novoa. Catedrático de Dereito mercantil nos XXV anos de cátedra, Universidad de Santiago Compostela, Santiago de Compostela, 1989, págs. 235 y ss.

Miguel A. FurOnEs (1980), El mundo de la publicidad, Salvat, Barcelona.

Carmen García Pérez (2009), “Comentario a los artículos 15, 16, 17 y 18”, en Emilio LÁzARO (coord.), Comentario a la Ley General de Publicidad, Civitas - Thomson Reuter, Cizur Menor, págs. 316 y ss.

M. ángeles GonzÁlez Lobo y M. a Dolores Prieto del Pino (2009), Manual de publicidad, ESIC, Madrid.

Alfonso GonZÁlez Gozalo (2001), “La tutela de los formatos televisivos”, Pe I., núm. 9, 2001, págs. 29 y ss.

Rafael JimÉnEZ DE PARGA (2003), “Protección de las creaciones publicitarias”, en Estudios jurídicos en homenaje al profesor Luis Díez-Picazo, Madrid, Civitas, pág. 5919 y ss.

Emilio LÁzAro (2009), “Comentario a los artículos 22 y 23”, en Emilio LÁzAro (coord.), Comentario a la Ley General de Publicidad, Civitas - Thomson Reuter, Cizur Menor, pág. 383 y ss.

Ulrich LOEWENHEIM (2020), en Ulrich LOEWENHEIM, Matthias LeITSNER y Ansgar OHLy, (eds.), Schricker / Loewenheim Urheberrecht, 6 . $^{\text {a }}$ ed., C.H. Beck, Munich.

Luis A. MARco ARCALÁ (2014), “La contratación publicitaria (I): los contratos de publicidad y de difusión publicitaria", en José A. GARCía CRUCES (dir.), Tratado de Derecho de la competencia y de la publicidad, T. II, Tirant lo Blanch, Valencia, págs. 2041 y ss.

Concepción SAIZ (1998), “Las obras audiovisuales de carácter publicitario y el Derecho de autor”, ADI, 1998, págs. 245 y ss.

Rafael SÁNCHEZ ARISTI (2000), “Las ideas como objeto protegible por la propiedad intelectual”, Pe. i., núm. 4, 2000, págs. 25 y ss.

Rafael SÁNCHEZ ARISTI (2020), en Rodrigo BERCOVITZ y otros (coord.), Tratado de contratos, T. IV, Tirant lo Blanch, Valencia, págs. 5983 y ss. 
Gerhard SCHRICKER (1996), “Die Urheberrechtsschutz von Werbeschöpfungen, Webeideen, Werbekonceptionen und Werbekampagnen", GRUR, 1996, págs. 815 y ss.

Gerhard SCHRICKER (2004), “Werbekonceptionen und Fernsehformaten. Eine Herausforderung für den urheberrechtlichen Werkbegriff?", GRUR Int, 2004, págs. 923 y ss.

Anxo TAтo (2017), “La protección de las creaciones publicitarias”, InDret, 1/2017 (www.indret.com).

\section{Tabla de sentencias citadas}

\begin{tabular}{|c|c|c|c|}
\hline Sala y Fecha & Fuente & Magistrado Ponente & Partes \\
\hline $\begin{array}{l}\text { STJUE, } 4^{a}, \quad 16.7 .2009, \\
\text { asunto C-5/08 }\end{array}$ & ECLI:EU:C:2009:465 & J. Malenovský & $\begin{array}{l}\text { Infopaq International A/S } \\
\text { contra Danske Dagblades } \\
\text { Forening }\end{array}$ \\
\hline $\begin{array}{l}\text { STJUE, } 3^{a}, 22.12 .2010, \\
\text { asunto C-393/09 }\end{array}$ & ECLI:EU:C:2010:816 & G. Arestis & $\begin{array}{l}\text { Bezpečnostír softwarová } \\
\text { asociace c. Ministerstoo } \\
\text { kultury }\end{array}$ \\
\hline $\begin{array}{l}\text { STJUE, Gran Sala, } \\
2.5 .2012 \text {, asunto C- } \\
406 / 10\end{array}$ & ECLI:EU:C:2012:259 & G. Arestis & $\begin{array}{l}\text { SAS Institute Inc. contra } \\
\text { World Programming Ltd }\end{array}$ \\
\hline $\begin{array}{l}\text { STJUE, Gran Sala, } \\
\text { 13.11.2018, asunto C- } \\
310 / 17\end{array}$ & ECLI:EU:C:2018:899 & M. Vilaras & $\begin{array}{l}\text { Levola Hengelo } B V \quad \text { c. } \\
\text { Smilde Foods } B V\end{array}$ \\
\hline $\begin{array}{l}\text { STJUE, Gran Sala, } \\
29.7 .2019 \text {, asunto C- } \\
469 / 17\end{array}$ & ECLI:EU:C:2019:623 & M. Ilešič & $\begin{array}{l}\text { Funke Medien NRW } \\
\text { GmbH c. Bundesrepublik } \\
\text { Detschland }\end{array}$ \\
\hline $\begin{array}{l}\text { STJUE, } 3^{a}, 12.9 .2019, \\
\text { asunto C-683/17 }\end{array}$ & ECLI:EU:C:2019:721 & J. Malenovský & $\begin{array}{l}\text { Cofemel - Sociedade de } \\
\text { Vestuário, S.A. c. G-Star } \\
\text { Raw CV }\end{array}$ \\
\hline $\begin{array}{l}\text { STJUE, } 5^{a}, 11.8 .2020, \\
\text { asunto C-833/18 }\end{array}$ & ECLI:EU:C:2020:461 & E. Juhász & $\begin{array}{l}\text { SI y Brompton Bicycle Ltd } \\
\text { c. Chedech/Get2Get }\end{array}$ \\
\hline $\begin{array}{l}\text { STS, } 1^{a} \text {, núm. 663/1999 } \\
\text { de } 15 \text { de julio }\end{array}$ & ECLI:ES:TS:1999:5135 & $\begin{array}{l}\text { A. Barcala Trillo- } \\
\text { Figueroa }\end{array}$ & "Los Mundos de Yupi" \\
\hline $\begin{array}{l}\text { STS, } 1^{a} \text {, núm. } 792 / 2010 \\
\text { de } 9 \text { de diciembre }\end{array}$ & ECLI:ES:TS:2010:7202 & J. R. Ferrándiz Gabriel & "La botica de la abuela" \\
\hline $\begin{array}{l}\text { STS, } 1 .^{a} \text {, núm. 588/2014 } \\
\text { de } 22 \text { de octubre }\end{array}$ & ECLI:ES:TS:2014:4623 & R. Sarazá Jimena & "A todo corazón" \\
\hline $\begin{array}{l}\text { STS, } 1^{a} \text {, núm. } 504 / 2019 \\
\text { de } 30 \text { septiembre }\end{array}$ & ECLI:ES:TS:2019:2852 & R. Sarazá Jimena & "Pasapalabra" \\
\hline $\begin{array}{l}\text { SAP Barcelona, Civil } \\
15^{a}, 28.5 .2003\end{array}$ & AC $2003 \backslash 960$ & J.-Ll. Forgas Folch & "Lara Croft" \\
\hline $\begin{array}{l}\text { SAP Barcelona, Civil } \\
15^{a}, 25.2 .2020\end{array}$ & ECLI:ES:APB:2020:1094 & J. $M^{a}$ Fernández Seijo & "Dial Vision" \\
\hline $\begin{array}{l}\text { SAP Madrid, Civil 28, } \\
\text { 11.1.2007 }\end{array}$ & ECLI:ES:APM:2007:625 & R. Sarazá Jimena & $\begin{array}{l}\text { "Comunicación } \\
\text { persuasiva" }\end{array}$ \\
\hline $\begin{array}{l}\text { SAP Madrid, Civil 28, } \\
\text { 11.10.2007 }\end{array}$ & ECLI:ES:APM:2007:14578 & E. García García & "Lotería Elegida" \\
\hline $\begin{array}{l}\text { SAP Madrid, Civil 28, } \\
\text { 8.4.2011 }\end{array}$ & ECLI: ES:APM:2011:2697 & $M^{a}$ Á. Rodríguez Alique & "Corazones púrpuras" \\
\hline $\begin{array}{l}\text { SAP Madrid, Civil 28, } \\
\text { 20.9.2016 }\end{array}$ & ECLI:ES:APM:2016:12100 & Á. Gago Peco & "Pasapalabra" \\
\hline $\begin{array}{l}\text { SAP Madrid, Civil 28, } \\
\text { 19.10.2020 }\end{array}$ & ECLI:ES:APM:2020:12903 & P. Ma Gómez Sánchez & "La reina de España" \\
\hline
\end{tabular}

